\title{
Effects of flow direction and thermal short-circuiting on the performance of coaxial ground heat exchangers
}

\author{
E. Zanchini, S. Lazzari and A. Priarone \\ Dipartimento di Ingegneria Energetica, Nucleare e del Controllo Ambientale \\ Università di Bologna \\ Viale Risorgimento 2, I-40136, Bologna, Italia \\ Phone/Fax number:+39 0512093295 / +39 051 2093296, e-mail: enzo.zanchini@unibo.it
}

\begin{abstract}
The effects of flow direction and thermal short-circuiting on the performance of coaxial ground heat exchangers are studied by finite-element simulations, performed through COMSOL Multiphysics 3.4 (CComsol, Inc.). The real 2-D axisymmetric unsteady heat conduction and convection problem is considered. The distribution of the fluid bulk temperature in the inner circular tube is determined by means of the "weak boundary form" boundary condition available in COMSOL Multiphysics; the laminar convective heat transfer in the outer annular passage is simulated directly. Two Coaxial Ground Heat Exchangers (CGHEs) with the same length but different cross sections are examined; moreover, two values of the ground thermal conductivity, as well as two materials for the inner tube wall are considered. The results point out that the annulus-in flow direction (fluid inlet in the outer annular passage) is more efficient than the center-in flow direction (fluid inlet in the inner circular tube) and that the effect of shortcircuiting is not very important, if the annulus-in flow direction is employed. Indeed, with this inlet configuration the energy loss for thermal short-circuiting is less than $1 \%$ for time intervals longer than 1 hour.
\end{abstract}

\section{Key words}

Ground Coupled Heat Pumps, Vertical Ground Heat Exchangers, Thermal Short-Circuiting, Flow Direction, Finite Element Simulations.

\section{Introduction}

Ground Coupled Heat Pumps (GCHPs) are based on heat transfer between the ground and a fluid, usually water, which circulates in tubes buried in the soil. Two different kinds of heat exchangers are employed: horizontal heat exchangers and vertical heat exchangers or Borehole Heat Exchangers (BHEs). BHEs have three different geometries:

1) single U-tube: only one U-bent polyethylene tube is placed in the borehole, which is then grouted;
2) double U-tube: two U-bent polyethylene tubes are placed in the borehole, which is then grouted;

3) two coaxial circular tubes, namely an internal polyethylene tube and an external tube, either inserted in a borehole (then grouted) or directly driven into the soil. The external tube is usually made of stainless steel; this choice is mandatory if the tube is driven into the soil.

The total length of a BHE necessary for a plant is usually determined by a method recommended by ASHRAE [1], which was proposed by Ingersoll and Zobel [2] and adjusted by Kavanaugh [3]. The final expressions for the total length require the knowledge of the effective thermal conductivity of the soil, $k_{g}$, of the effective thermal diffusivity of the soil, $\alpha_{g}$, and of the borehole thermal resistance per unit length, $R_{b}$. The latter is determined mainly by the geometry of the borehole and by the thermal conductivity $k_{s}$ of the grout (which is always present in U-tube BHEs). In order to determine $k_{g}, \quad \alpha_{g}$ and $R_{b}$, a Thermal Response Test (TRT) is performed, according to the procedure prescribed by ASHRAE [1]. First, the undisturbed ground temperature $T_{g}$ is determined, by one of the methods suggested in Ref. [4]. Then, by means of electric resistances, a constant power is supplied to the water which flows in the BHE and the following quantities are measured and recorded: the inlet fluid temperature $T_{i n}$, the outlet fluid temperature $T_{\text {out }}$, the arithmetic mean fluid temperature $T_{m}=$ $\left(T_{\text {in }}+T_{\text {out }}\right) / 2$, the mass flow rate $\dot{m}$ and the electric power $\dot{Q}_{e l}$. The TRT has a minimum duration of 48 hours. The experimental data are processed by analytical or numerical methods to obtain best estimates of $k_{g}, \alpha_{\mathrm{g}}$ and $R_{b}$.

The simplest method for the evaluation of a TRT is the analytical line heat source method, described, for instance, in Refs. [5, 6]. It considers the BHE as a linear power source within an infinite solid medium, which supplies to the medium a constant power per unit length 
$q_{l}$. By employing an approximate form of the analytical solution for the temperature field $T(r, \tau)$, one obtains:

$$
T_{m}(\tau)-T_{g}=\frac{q_{l}}{4 \pi k_{g}} \ln \tau+C
$$

where $\tau$ is time, starting from the beginning of the heating process, and $C$ is a constant given by

$$
C=q_{l}\left\{R_{b}+\frac{1}{4 \pi k_{g}}\left[\ln \left(\frac{4 \alpha_{g}}{a^{2}}\right)-\gamma\right]\right\} .
$$

In Eq. (2), $a$ is the borehole radius and $\gamma \approx 0.5772$ is Eulero constant.

Since the line heat source method does not take into account the heat capacity of the materials which form the BHE, Eqs. (1) and (2) are valid only if the time elapsed from the beginning of the heating process is greater than 15 hours. By means of a linear interpolation of the experimental values of $T_{m}(\tau)-T_{\mathrm{g}}$ versus $\ln \tau$, one determines $k_{g}$ and $C$. Then, one fixes a plausible value of $\alpha_{g}$ and determines $R_{b}$ through Eq. (2). Clearly, the method contains heavy approximations; nevertheless, if correctly applied to sufficiently long TRTs, it yields acceptable values of $k_{g}$. The approximation on $R_{b}$ is worse, also because it is affected by the uncertainty on the value assumed for $\alpha_{g}$.

Most of the research on BHEs carried out in the last decade has concerned the development of methods which yield more precise values of $\alpha_{g}$ and $R_{b}$. For this purpose, numerical models for the evaluation of TRTs, as well as analytical and numerical studies of heat transfer mechanisms within BHEs have been developed.

In Ref. [7], a 2-D finite-volume numerical method for the simulation of unsteady heat transfer between a single Utube BHE and the soil is presented. The method is validated by comparison with analytical models. In Ref. [8], the authors report the experimental results of some TRTs as well as the results of numerical evaluations of the TRTs, performed by the method proposed in Ref. [7]. The numerical evaluation has allowed the authors to determine the thermal conductivities $k_{g}$ and $k_{s}$. In Ref. [9], four methods for the evaluation of TRTs are applied to the same data set and compared; in each case, the parameters $k_{g}$ and $R_{b}$ are evaluated. The methods are: two different applications of the line heat source method, a cylindrical heat source analytical method [9, 10], a 1-D finite-difference numerical method. The authors conclude that, while the line heat source method and the numerical method are in fair agreement with each other, the cylindrical heat source method overestimates the thermal conductivity of the ground and does not seem reliable.

In Ref. [4], two methods for measuring the undisturbed ground temperature are recommended: temperature logging along the borehole; circulating water through the borehole with electric resistances turned off and measuring the outlet fluid temperature at short time intervals until all the fluid contained in the borehole has come out.
Roth et al. [5] compare two methods for the evaluation of a TRT performed in Latin America: the analytical evaluation by the line heat source method and a 1-D numerical evaluation. In the numerical method, the borehole is sketched as the union of three domains: an internal water cylinder, a thin cylindrical layer without thermal inertia which represents the convective thermal resistance, a cylindrical layer which represents the grout. In Ref. [11], the authors study the heat transfer within a BHE and exclude the ground. They consider steady-state conditions and assume that the temperature of the external surface of the BHE is uniform. They neglect the heat conduction in the vertical direction and, by employing some other approximations, they evaluate analytically the distribution of the fluid bulk temperature along the channels of a BHE. They consider both single U-tube and double U-tube BHEs. By employing the obtained temperature distributions, they evaluate the borehole thermal resistance as

$$
R_{b}=\frac{T_{m}-T_{w}}{q_{l}},
$$

where $T_{w}$ is the temperature of the external surface of the BHE. The results point out that the thermal resistance of double U-tube BHEs is about 30\% lower than that of single U-tube BHEs.

Lamarche and Beauchamp [12] propose a new analytical model for the evaluation of TRTs, valid also in the initial part of the heating process, and compare the analytical results with simulations obtained by means of COMSOL Multiphysics. The borehole is sketched as a water cylinder surrounded by a ring of grout, buried in the soil. Two thermal conditions are considered: uniform and constant heat flux at the internal surface of the grout; uniform water temperature and convective heat flux between water and grout. The paper refers to single Utube BHEs; analytical results are in fair agreement with numerical simulations.

Marcotte and Pasquier [13] perform 3-D numerical simulations with COMSOL Multiphysics, with reference to a single U-tube BHE which absorbs a constant thermal power from the ground. They obtain the time evolution of the fluid bulk temperature distribution along the tubes. The results show that the true mean fluid temperature, $T_{f}$, does not coincide with the arithmetic mean fluid temperature, $T_{m}$, and that if $T_{m}$ is employed instead of $T_{f}$ to evaluate $R_{b}$ by Eq. (3), then $R_{b}$ is overestimated. The authors then propose a new expression of $T_{f}$ for the evaluation of TRTs.

This short overview of relevant references reveals that most of the literature is devoted to the study of U-tube BHEs, which, indeed, are the most commonly used. Even for this geometry, the effect of thermal short-circuiting is seldom considered. In the quoted references, it is taken into account only in Refs. [11] and [13] and, even there, is not clearly evidenced. On the other hand, to account for thermal short-circuiting, a 4 to $6 \%$ increase in the effective thermal resistance of ground for a daily heat pulse is recommended by ASHRAE [1], in the use of the expressions for sizing U-tube BHEs piped in parallel. 
The value of this increase parameter would deserve a deeper analysis. In addition, also vertical ground heat exchangers with coaxial tubes are now employed in Northern Italy, in the Padana Plain, where coaxial heat exchangers with an external stainless steel tube are directly driven into the soil, up to a depth of about $20 \mathrm{~m}$. Since no bore is present in most applications of coaxial heat exchangers with the ground, they will be called Coaxial Ground Heat Exchangers (CGHEs). To our knowledge, no data are available in the literature to take into account the effects of thermal short-circuiting for CGHEs. Therefore, an analysis of the effects of thermal short-circuiting for CGHEs seems necessary, not only for a correct sizing of these heat exchangers, but also to understand whether techniques to reduce this effect could be useful to improve the thermal performance. Another relevant technical information for the application of CGHEs is the knowledge of the change in performance which occurs if the flow direction is reversed. In fact, a CGHE can operate in two different ways:

a) fluid inlet in the external annular passage;

b) fluid inlet in the internal tube.

The principal aim of this paper is to evaluate the effects of thermal short-circuiting on the performance of CGHEs and to determine how much the performance of a CGHE changes if the flow direction is reversed. A second aim is to evaluate the increase in performance which can be obtained by a slight modification of the cross section of a CGHE. For these purposes, two CGHEs are considered: the first is a CHGE currently used in Italy; the second is a slightly modified version of the first. Results are obtained through finite-element numerical simulations performed by means of the software package COMSOL Multiphysics 3.4 (C Comsol, Inc.).

\section{Simulation method}

Both CGHEs modelled have length $L=20 \mathrm{~m}$. The real 3$\mathrm{D}$ unsteady conditions of the heat transfer problem are considered. However, on account of the axial symmetry of both the geometry and the initial and boundary conditions, a 2-D axisymmetric model with a cylindrical coordinate system $(r, z)$ is employed, as sketched in Figure 1. Both the CGHE and a portion of the surrounding soil are included in the computational domain; the latter is a cylinder, coaxial with the CGHE, with radius $r_{0}=4 \mathrm{~m}$ and length $L_{0}=24 \mathrm{~m}$. Thus, also a ground layer $4 \mathrm{~m}$ thick under the CGHE is modelled.

The first CGHE, which will be called CGHE 1, is a coaxial ground heat exchanger commonly used in Northern Italy, directly driven into the soil. It has an inner tube made either of high density polyethylene, PE$\mathrm{Xa}$, or of high molecular weight random copolymer polypropylene PP-R80: the external diameter of the inner tube is $32 \mathrm{~mm}$, while the internal diameter thereof is 26.2 $\mathrm{mm}$. The outer tube is made of AISI 304 steel; it has an external diameter of $50 \mathrm{~mm}$ and a wall thickness of 2 $\mathrm{mm}$. The second CGHE, which will be called CGHE 2, has a slightly modified geometry, designed to increase the fluid velocity in the outer annular passage and to reduce it in the inner circular tube. In CGHE 2, the inner tube has an external diameter of $40 \mathrm{~mm}$ and an internal diameter of $32.6 \mathrm{~mm}$, while the outer AISI 304 steel tube has an external diameter of $54 \mathrm{~mm}$ and a thickness of 2 $\mathrm{mm}$. Reference is made to real commercial tubes. Relevant geometrical parameters, material properties and working conditions are listed in Table I.

The mass flow rate considered is $11.5 \mathrm{dm}^{3} / \mathrm{min}$, with an inlet water temperature of $4^{\circ} \mathrm{C}$ (winter operation). In these conditions, the water flow is turbulent in the inner tube and laminar in the outer annular passage. Thus, in the inner tube the forced convection heat transfer phenomena are difficult to simulate, while the convection coefficient is not strongly dependent on the thermal boundary condition. On the contrary, in the outer annular passage the laminar forced convection heat transfer can be easily simulated, while the convection coefficients between fluid and walls are strongly dependent on the ratio between the wall heat fluxes [14], which is unknown, non uniform along $z$ and time dependent.

For this reason, the internal flow is not simulated. In the inner tube, the distribution of the fluid bulk temperature $T_{f}$ along the flow direction $z$ and the heat transfer between fluid and wall are determined by means of the so-called "weak boundary condition" available in COMSOL Multiphysics. In detail, the following energy balance equation for the fluid is coupled with the convective heat transfer boundary condition at $r=r_{1}$ (internal wall of the inner tube):

$$
A_{1} \rho_{f} c_{f} \frac{\partial T_{f}}{\partial \tau}= \pm \dot{V} \rho_{f} c_{f} \frac{\partial T_{f}}{\partial z}+h_{1} p_{1}\left(T_{r 1}-T_{f}\right) \text {. }
$$

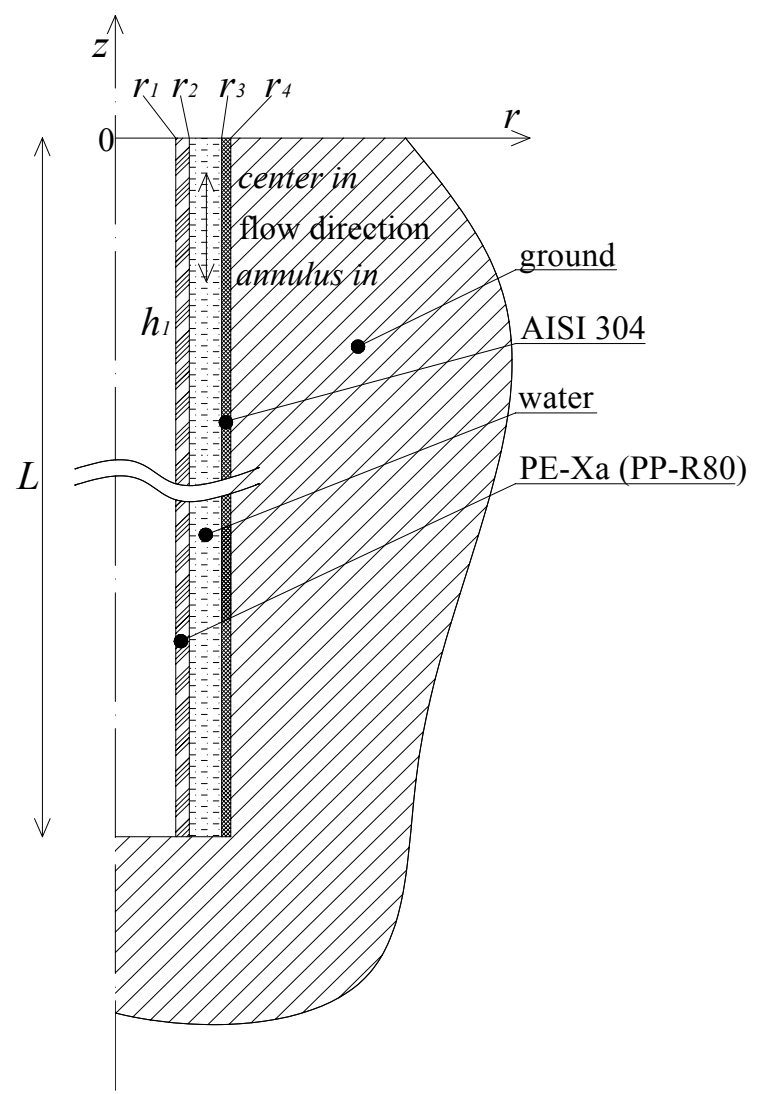

Fig. 1. Sketch of the computational domain. 
TABLE I. -Values of relevant geometrical parameters, thermal properties and working conditions.

\begin{tabular}{|c|c|c|}
\hline SYMBOL & VALUE & QUANTITY \\
\hline \multicolumn{3}{|c|}{ Geometrical data of CGHE 1} \\
\hline$r_{1}$ & 13.1 & Internal radius of inner tube [mm] \\
\hline$r_{2}$ & 16 & External radius of inner tube [mm] \\
\hline$r_{3}$ & 23 & Internal radius of outer tube $[\mathrm{mm}]$ \\
\hline$r_{4}$ & 25 & External radius of outer tube $[\mathrm{mm}]$ \\
\hline$L^{4}$ & 20 & Length $[\mathrm{m}]$ \\
\hline \multicolumn{3}{|c|}{ Geometrical data of CGHE 2} \\
\hline$r_{l}$ & 16.3 & Internal radius of inner tube $[\mathrm{mm}]$ \\
\hline$r_{2}$ & 20 & External radius of inner tube [mm] \\
\hline$r_{3}$ & 25 & Internal radius of outer tube [mm] \\
\hline$r_{4}$ & 27 & External radius of outer tube [mm] \\
\hline$L^{4}$ & 20 & Length $[\mathrm{m}]$ \\
\hline \multicolumn{3}{|c|}{ Thermal properties of AISI304 steel } \\
\hline$c_{a}$ & 500 & Specific heat capacity $[\mathrm{J} /(\mathrm{kg} \mathrm{K})]$ \\
\hline$k_{a}$ & 15 & Thermal conductivity $[\mathrm{W} /(\mathrm{m} \mathrm{K})]$ \\
\hline$\rho_{\mathrm{a}}$ & 7910 & Density $\left[\mathrm{kg} / \mathrm{m}^{3}\right]$ \\
\hline \multicolumn{3}{|c|}{ Thermal properties of high density polyethylene $P E-X a$} \\
\hline$c_{l}$ & 2300 & Specific heat capacity $[\mathrm{J} /(\mathrm{kg} \mathrm{K})]$ \\
\hline$k_{1}$ & 0.35 & Thermal conductivity $[\mathrm{W} /(\mathrm{m} \mathrm{K})]$ \\
\hline$\rho_{1}$ & 940 & Density $\left[\mathrm{kg} / \mathrm{m}^{3}\right]$ \\
\hline \multicolumn{3}{|c|}{$\begin{array}{l}\text { Thermal properties of high molecular weight random } \\
\text { copolymer polypropylene } P P-R 80\end{array}$} \\
\hline$c_{2}$ & 2000 & Specific heat capacity $[\mathrm{J} /(\mathrm{kg} \mathrm{K})]$ \\
\hline$k_{2}$ & 0.24 & Thermal conductivity $[\mathrm{W} /(\mathrm{m} \mathrm{K})]$ \\
\hline$\rho_{2}$ & 900 & Density $\left[\mathrm{kg} / \mathrm{m}^{3}\right]$ \\
\hline \multicolumn{3}{|c|}{ Thermal and rheological properties of water at $T=4.3^{\circ} \mathrm{C}$} \\
\hline$c_{p f}$ & 4207 & $\begin{array}{l}\text { Specific heat capacity at constant } \\
\text { pressure }[\mathrm{J} /(\mathrm{kg} \mathrm{K})]\end{array}$ \\
\hline$k_{f}$ & 0.5692 & Thermal conductivity $[\mathrm{W} /(\mathrm{m} \mathrm{K})]$ \\
\hline$\rho_{f}$ & 999.97 & Density $\left[\mathrm{kg} / \mathrm{m}^{3}\right]$ \\
\hline$\mu_{f}$ & 1.552 & Dynamic viscosity [mPa s] \\
\hline \multicolumn{3}{|c|}{ Thermal properties of ground } \\
\hline$(\rho c)_{g}$ & 2000 & $\begin{array}{l}\text { Heat capacity per unit volume }\left[\mathrm{J} /\left(\mathrm{m}^{3}\right.\right. \\
\mathrm{K})]\end{array}$ \\
\hline$k_{g l}$ & 1.4 & Thermal conductivity $1[\mathrm{~W} /(\mathrm{m} \mathrm{K})]$ \\
\hline$k_{g 2}$ & 2.8 & Thermal conductivity $2[\mathrm{~W} /(\mathrm{m} \mathrm{K})]$ \\
\hline \multicolumn{3}{|c|}{ Working conditions } \\
\hline$T_{\text {in }}$ & 4 & Water inlet temperature $\left[{ }^{\circ} \mathrm{C}\right]$ \\
\hline$T_{s}$ & 4 & Ground surface temperature $\left[{ }^{\circ} \mathrm{C}\right]$ \\
\hline$T_{g}$ & 14 & Undisturbed ground temperature $\left[{ }^{\circ} \mathrm{C}\right]$ \\
\hline$\dot{\dot{V}}$ & 11.5 & Water flow rate $\left[\mathrm{dm}^{3} / \mathrm{min}\right]$ \\
\hline
\end{tabular}

In Eq. (4): $A_{1}=\pi r_{1}^{2}$ is the inner tube cross-section area, $\tau$ is time, $p_{1}=2 \pi r_{1}$ is the internal wall perimeter per unit length, $T_{r 1}$ is the internal wall temperature, $h_{1}$ is the convection heat transfer coefficient; the sign + in the first term of the right hand side holds for downward flow (water inlet in the inner tube), while the sign - in the same term holds for upward flow (water inlet in the annular passage). The value to be assigned to the internal Nusselt number and, therefore, to $h_{l}$ is determined by means of the Churchill correlation [15]. One obtains $h_{1} \approx$ $1520 \mathrm{~W} /\left(\mathrm{m}^{2} \mathrm{~K}\right)$ for CGHE 1 (Reynolds number $R e=$ 6001 ) and $h_{1} \approx 968 \mathrm{~W} /\left(\mathrm{m}^{2} \mathrm{~K}\right.$ ) for CGHE 2 (Reynolds number $R e=4823$ ).

In the annular passage, the forced convection flow is considered as fully developed, because the length of the duct is three orders of magnitude higher than the duct mean diameter. The laminar fluid velocity profile $U(r)$ in the annular duct, which has internal radius $r_{2}$ and external radius $r_{3}$, is given by [16]

$$
U(r)=U_{m} \frac{2\left\{\left[\left(\frac{r_{2}}{r_{3}}\right)^{2}-1\right] \ln \frac{r}{r_{3}}-\left[\left(\frac{r}{r_{3}}\right)^{2}-1\right] \ln \frac{r_{2}}{r_{3}}\right\}}{1-\left(\frac{r_{2}}{r_{3}}\right)^{2}+\left[1+\left(\frac{r_{2}}{r_{3}}\right)^{2}\right] \ln \frac{r_{2}}{r_{3}}},
$$

where $U_{m}=\dot{V} /\left[\pi\left(r_{3}^{2}-r_{2}^{2}\right)\right]$ is the mean fluid velocity in the duct, which is positive for upward flow (water inlet in the inner tube) and negative for downward flow (water inlet in the annular passage). The convection heat transfer in the annular duct is simulated with the velocity distribution given by Eq. (5).

The differential equations to be solved are

$$
\rho_{f} c_{p f}\left[\frac{\partial T}{\partial \tau}+(\mathbf{U} \cdot \nabla) T\right]=k_{f} \nabla^{2} T
$$

with $\mathbf{U}=(0, U)$ and $U=U(r)$ given by Eq. (5), in the annular duct;

$$
\rho c \frac{\partial T}{\partial \tau}=k \nabla^{2} T
$$

with the thermal properties of the material present in the subdomain considered, for all the other subdomains.

As initial condition, a depth-dependent temperature distribution in the soil $T_{0}(z)$ is considered, which accounts both for the steep temperature gradient near the ground surface and for the geothermal gradient. The following expression of $T_{0}(z)$ has been assumed,

$$
T_{0}(z)=T_{g}+\left(T_{s}-T_{g}\right) e^{z}+H(-10-z) \cdot T G \cdot(-10-z),
$$

where $T_{g}$ is the undisturbed ground temperature, $H$ is the Heaviside unit step function, $T G=0.03^{\circ} \mathrm{C} / \mathrm{m}$ is the geothermal gradient and $-24 \mathrm{~m} \leq z \leq 0$. The same initial condition is adopted for the CGHE, which is assumed to be in thermal equilibrium with the ground. For $t>0$, the inlet water temperature $T_{i n}$ is prescribed and constant, as well as the surface ground temperature $T_{s}$. The external vertical and bottom surfaces of the modelled ground are kept at the constant temperature $T_{0}(z)$.

Clearly, the continuity conditions are imposed at the interfaces between different materials, while the "outflow pressure" condition is imposed at the fluid outlet.

In order to grant that the results are independent of the domain extension, most simulations have been repeated by replacing the boundary condition $T=T_{0}(z)$, at the external vertical and bottom surfaces, with the boundary condition of adiabatic surfaces. The check has always given the same results as those obtained with the first boundary condition.

A period of five days of operation, with fixed values of the water inlet temperature and of the volume flow rate, is considered for each CGHE. Clearly, the temperature changes are steeper during the first minutes and become much slower as time goes by. Therefore the following time steps are adopted in computations: $1 \mathrm{~s}$ for $0<\tau<60 \mathrm{~s}, \quad 5 \mathrm{~s}$ for $60 \mathrm{~s}<\tau<600 \mathrm{~s}, \quad 60 \mathrm{~s}$ for $600 \mathrm{~s}<\tau<3600 \mathrm{~s}, 600 \mathrm{~s}$ for $3600 \mathrm{~s}<\tau<43200 \mathrm{~s}, 7200 \mathrm{~s}$ for $43200 \mathrm{~s}<\tau<432000 \mathrm{~s}$. The thermal power $\dot{Q}$ 
exchanged between the CGHE and the surrounding soil, as a function of time, is determined as

$$
\dot{Q}=\int_{S} k_{g} \nabla T \cdot \mathbf{n} d S
$$

where $\nabla T$ is evaluated in the ground, $S$ is the boundary surface of the CGHE and $\mathbf{n}$ is the outward unit normal.

\section{Results}

In order to point out the effects of flow direction on the performance of a CGHE, two directions of the water flow in the tubes have been considered: water inlet in the outer annular passage, which will be denoted by annulus-in, water inlet in the inner tube, which will be denoted by center-in. Moreover, to point out the effects of thermal short-circuiting, three different thermal conductivities of the material which forms the inner tube have been considered: the thermal conductivity of polyethylene PE$\mathrm{Xa}, k_{1}=0.35 \mathrm{~W} /(\mathrm{mK})$; the thermal conductivity of polypropylene PP-R80, $k_{2}=0.24 \mathrm{~W} /(\mathrm{mK})$; a nearly vanishing thermal conductivity $k=0.0001 \mathrm{~W} /(\mathrm{mK})$, to simulate an adiabatic wall of the inner tube.

Finally, to investigate the influence of the thermal conductivity of the ground on the effects of flow direction and of thermal short-circuiting, two different kinds of ground have been considered: GROUND 1, with a low thermal conductivity, $k_{g 1}=1.4 \mathrm{~W} /(\mathrm{mK})$; GROUND 2 , with a high thermal conductivity, $k_{\mathrm{g} 2}=2.8 \mathrm{~W} /(\mathrm{mK})$. A standard value of the heat capacity per unit volume, 2 $\mathrm{MJ} /\left(\mathrm{m}^{3} \mathrm{~K}\right)$, has been considered for both grounds. All the calculations have been performed for two CGHEs: CGHE 1 and CGHE 2, with different geometrical features, summarized in Table I.

In order to ensure the grid independence of results, three different mapped meshes have been tested: Mesh 1, with about 13300 elements; Mesh 2, with about 22000 elements; Mesh 3, with about 29000 elements. A comparison of the results obtained with the different meshes is illustrated in Table II, where the values of the energy collected by CGHE 1 in GROUND 1 are reported for some time intervals after the start-up, in the annulusin configuration and with inner tube made of PE-Xa.

The results show that the discrepancies between Mesh 2 and Mesh 3 are very small. Therefore, Mesh 2 has been adopted for all the computations reported in the following. A sketch of Mesh 2 is represented in Figure 2. The main parameter analyzed is the energy collected by a CGHE as a function of time. The results for this parameter, for some selected time intervals, are reported in Tables III and IV, for all the considered cases.

TABLE II. - Energy collected by CGHE 1, calculated using Mesh 1, Mesh 2 and Mesh 3.

\begin{tabular}{|c|c|c|c|}
\hline \multicolumn{4}{|c|}{ Energy [MJ] CGHE 1, GROUND 1, PE-Xa, annulus-in } \\
\hline Time & $\begin{array}{c}\text { Mesh 1 } \\
\text { (13263 elements) }\end{array}$ & $\begin{array}{c}\text { Mesh 2 } \\
\text { (22185 elements) }\end{array}$ & $\begin{array}{c}\text { Mesh 3 } \\
\text { (29005 elements) }\end{array}$ \\
\hline $300 \mathrm{~s}$ & 0.4999 & 0.5042 & 0.5059 \\
\hline $900 \mathrm{~s}$ & 1.396 & 1.404 & 1.407 \\
\hline $3600 \mathrm{~s}$ & 4.269 & 4.279 & 4.278 \\
\hline $6 \mathrm{~h}$ & 17.54 & 17.53 & 17.57 \\
\hline $24 \mathrm{~h}$ & 54.25 & 54.23 & 54.31 \\
\hline 5 days & 210.9 & 211.2 & 211.4 \\
\hline
\end{tabular}

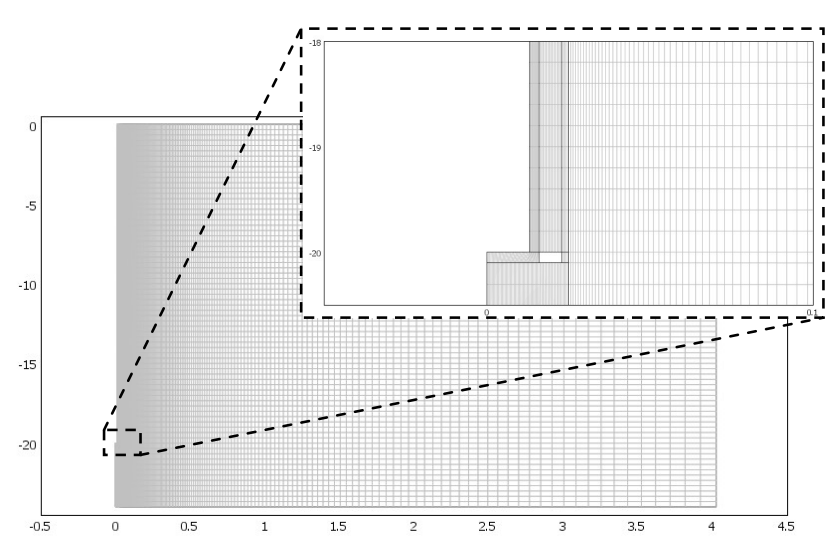

Fig. 2. Sketch of Mesh 2.

TABLE III. - Energy collected in different time periods for CGHE 1.

\begin{tabular}{|c|c|c|c|c|c|c|}
\hline \multirow[b]{3}{*}{ Time } & \multicolumn{6}{|c|}{ Energy [MJ] CGHE 1 - GROUND 1} \\
\hline & \multicolumn{3}{|c|}{ Annulus-in } & \multicolumn{3}{|c|}{ Center-in } \\
\hline & $P E-X a$ & PP-R80 & adiabatic & $P E-X a$ & PP-R80 & adiabatic \\
\hline $300 \mathrm{~s}$ & 0.504 & 0.510 & 0.519 & 0.345 & 0.355 & 0.391 \\
\hline $900 \mathrm{~s}$ & 1.40 & 1.41 & 1.42 & 1.28 & 1.28 & 1.32 \\
\hline $3600 \mathrm{~s}$ & 4.28 & 4.29 & 4.31 & 4.15 & 4.20 & 4.19 \\
\hline $6 \mathrm{~h}$ & 17.5 & 17.5 & 17.6 & 17.4 & 17.4 & 17.4 \\
\hline $24 \mathrm{~h}$ & 54.2 & 54.3 & 54.5 & 53.9 & 53.9 & 54.1 \\
\hline 5 days & 211 & 211 & 212 & 210 & 210 & 211 \\
\hline
\end{tabular}

\begin{tabular}{|c|c|c|c|c|c|c|}
\hline \multirow[b]{3}{*}{ Time } & \multicolumn{6}{|c|}{ Energy [MJ] CGHE 1 - GROUND 2} \\
\hline & \multicolumn{3}{|c|}{ Annulus-in } & \multicolumn{3}{|c|}{ Center-in } \\
\hline & $P E-X a$ & PP-R80 & adiabatic & $P E-X a$ & PP-R80 & adiabatic \\
\hline $300 \mathrm{~s}$ & 0.618 & 0.625 & 0.636 & 0.415 & 0.427 & 0.471 \\
\hline $900 \mathrm{~s}$ & 1.80 & 1.81 & 1.83 & 1.61 & 1.62 & 1.67 \\
\hline $3600 \mathrm{~s}$ & 5.94 & 5.95 & 6.00 & 5.71 & 5.77 & 5.78 \\
\hline $6 \mathrm{~h}$ & 25.0 & 26.5 & 26.7 & 26.0 & 26.1 & 26.2 \\
\hline $24 \mathrm{~h}$ & 86.1 & 86.3 & 86.9 & 85.1 & 85.2 & 85.5 \\
\hline 5 days & 349 & 349 & 352 & 345 & 345 & 347 \\
\hline
\end{tabular}


TABLE IV. - Energy collected in different time periods for CGHE 2.

\begin{tabular}{|c|c|c|c|c|c|c|}
\hline \multirow[b]{3}{*}{ Time } & \multicolumn{6}{|c|}{ Energy [MJ] CGHE 2 - GROUND 1} \\
\hline & \multicolumn{3}{|c|}{ Annulus-in } & \multicolumn{3}{|c|}{ Center-in } \\
\hline & $P E-X a$ & PP-R80 & adiabatic & $P E-X a$ & PP-R80 & adiabatic \\
\hline $300 \mathrm{~s}$ & 0.601 & 0.608 & 0.628 & 0.349 & 0.364 & 0.415 \\
\hline $900 \mathrm{~s}$ & 1.60 & 1.61 & 1.64 & 1.40 & 1.42 & 1.47 \\
\hline $3600 \mathrm{~s}$ & 4.71 & 4.75 & 4.76 & 4.56 & 4.59 & 4.60 \\
\hline $6 \mathrm{~h}$ & 18.8 & 18.8 & 18.9 & 18.6 & 18.6 & 18.7 \\
\hline $24 \mathrm{~h}$ & 57.3 & 57.4 & 57.7 & 56.9 & 57.1 & 57.2 \\
\hline 5 days & 221 & 221 & 222 & 219 & 220 & 221 \\
\hline
\end{tabular}

\begin{tabular}{|c|c|c|c|c|c|c|}
\hline \multirow[b]{3}{*}{ Time } & \multicolumn{6}{|c|}{ Energy [MJ] CGHE 2 - GROUND 2} \\
\hline & \multicolumn{3}{|c|}{ Annulus-in } & \multicolumn{3}{|c|}{ Center-in } \\
\hline & $P E-X a$ & PP-R80 & adiabatic & $P E-X a$ & PP-R80 & adiabatic \\
\hline $300 \mathrm{~s}$ & 0.744 & 0.751 & 0.779 & 0.419 & 0.438 & 0.502 \\
\hline $900 \mathrm{~s}$ & 2.09 & 2.10 & 2.15 & 1.79 & 1.82 & 1.89 \\
\hline $3600 \mathrm{~s}$ & 6.68 & 6.66 & 6.73 & 6.38 & 6.42 & 6.49 \\
\hline $6 \mathrm{~h}$ & 28.8 & 28.8 & 29.0 & 28.3 & 28.4 & 28.8 \\
\hline $24 \mathrm{~h}$ & 92.2 & 92.4 & 92.9 & 91.1 & 91.4 & 92.0 \\
\hline 5 days & 370 & 370 & 372 & 365 & 366 & 368 \\
\hline
\end{tabular}

TABLE V. - Percent difference between energy collected with flow direction center-in and energy collected with flow direction annulus-in.

\begin{tabular}{|c|c|c|c|}
\hline \multicolumn{5}{|c|}{ CGHE 1 - GROUND 1 } \\
\hline Time & $\boldsymbol{P E}-\boldsymbol{X} \boldsymbol{a}$ & $\boldsymbol{P P}$-R80 & adiabatic \\
\hline $300 \mathrm{~s}$ & -31.59 & -30.38 & -24.60 \\
\hline $900 \mathrm{~s}$ & -9.08 & -9.18 & -7.27 \\
\hline $3600 \mathrm{~s}$ & -2.91 & -2.21 & -2.63 \\
\hline $6 \mathrm{~h}$ & -0.93 & -0.69 & -1.10 \\
\hline $24 \mathrm{~h}$ & -0.68 & -0.61 & -0.81 \\
\hline 5 days & -0.66 & -0.67 & -0.26 \\
\hline
\end{tabular}

\begin{tabular}{|c|c|c|c|}
\hline \multicolumn{5}{|c|}{ CGHE 1 - GROUND 2 } \\
\hline Time & $\boldsymbol{P E}-\boldsymbol{X} \boldsymbol{a}$ & $\boldsymbol{P P}-\boldsymbol{R} 80$ & adiabatic \\
\hline $300 \mathrm{~s}$ & -32.93 & -31.71 & -25.92 \\
\hline $900 \mathrm{~s}$ & -10.53 & -10.49 & -8.64 \\
\hline $3600 \mathrm{~s}$ & -3.78 & -2.96 & -3.53 \\
\hline $6 \mathrm{~h}$ & -1.70 & -1.53 & -1.98 \\
\hline $24 \mathrm{~h}$ & -1.17 & -1.36 & -1.54 \\
\hline 5 days & -1.28 & -1.25 & -1.32 \\
\hline
\end{tabular}

\begin{tabular}{|c|c|c|c|}
\hline \multicolumn{5}{|c|}{ CGHE 2 - GROUND 1 } \\
\hline Time & $\boldsymbol{P E}-\boldsymbol{X} \boldsymbol{a}$ & $\boldsymbol{P P}-\boldsymbol{R} 80$ & adiabatic \\
\hline $300 \mathrm{~s}$ & -41.92 & -40.13 & -33.99 \\
\hline $900 \mathrm{~s}$ & -12.09 & -11.85 & -10.47 \\
\hline $3600 \mathrm{~s}$ & -3.23 & -3.33 & -3.40 \\
\hline $6 \mathrm{~h}$ & -1.14 & -1.05 & -1.22 \\
\hline $24 \mathrm{~h}$ & -0.69 & -0.56 & -0.92 \\
\hline 5 days & -0.58 & -0.71 & -0.42 \\
\hline
\end{tabular}

\begin{tabular}{|c|c|c|c|}
\hline \multicolumn{5}{|c|}{ CGHE 2 - GROUND 2 } \\
\hline Time & $\boldsymbol{P E}$ - $\boldsymbol{X} \boldsymbol{a}$ & $\boldsymbol{P P}-\boldsymbol{R} 80$ & adiabatic \\
\hline $300 \mathrm{~s}$ & -43.72 & -41.71 & -35.53 \\
\hline $900 \mathrm{~s}$ & -14.27 & -13.36 & -12.09 \\
\hline $3600 \mathrm{~s}$ & -4.47 & -3.73 & -3.67 \\
\hline $6 \mathrm{~h}$ & -1.75 & -1.48 & -0.98 \\
\hline $24 \mathrm{~h}$ & -1.25 & -1.05 & -0.96 \\
\hline 5 days & -1.18 & -1.13 & -1.01 \\
\hline
\end{tabular}

\section{A. Effect of flow direction}

The effect of flow direction on the thermal performance of CGHEs is illustrated in Table V, where the percent difference between the energy collected with the flow direction center-in and that collected with the flow direction annulus-in is reported, respectively for CGHE 1 in GROUND 1, CGHE 1 in GROUND 2, CGHE 2 in GROUND 1 and CGHE 2 in GROUND 2. In all cases, the results are negative, i.e., the annulus-in flow direction is preferable to the center-in flow direction. The effect is important in the first 5 minutes, where it can be higher than $40 \%$, remains important for about 15 minutes (8$13 \%$ ), then decreases and becomes lower than $2 \%$ after 6 hours. The effect is more important in the higher conductivity ground and for the higher efficiency CGHE. The reason for the higher performance of a CGHE which operates with the annulus-in flow direction, in the first minutes, is as follows. In the annulus-in configuration, the cold inlet water flows directly at contact with the AISI external tube, starting from the first instants of operation. On the contrary, if the center-in flow direction is adopted, the cold inlet water must first circulate along the whole inner tube before reaching the contact with the outer AISI wall of the external annular passage, at the bottom of the CGHE.

\section{B. Effect of thermal short-circuiting}

The effect of thermal short-circuiting on the performance of CGHEs is illustrated in Table VI, where the percent energy loss due to short-circuiting (with respect to the ideal case of adiabatic inner wall) is reported, respectively for CGHE 1 in GROUND 1, CGHE 1 in GROUND 2, CGHE 2 in GROUND 1 and CGHE 2 in GROUND 2.

As is shown by the results reported in Table VI, the effect of thermal short-circuiting on the performance of CGHEs 
is not very important, especially for the recommendable flow direction, annulus-in, i.e., with fluid inlet in the outer annular passage. For this flow configuration, the energy loss is higher than $4 \%$ only for CGHE 2 (the more efficient one) for a time interval of 5 minutes after the start-up of the CGHE. Then, it decreases rapidly and becomes lower than $1 \%$ for time intervals longer than 1 hour. For the center-in flow direction, i.e., with fluid inlet in the central tube, the effect of thermal short-circuiting can be very important during the first 5 minutes, where it can exceed $12 \%$. Indeed, the first 5 minutes are a very critical time interval for the operation of a CGHE in the center-in configuration. In fact, the cold inlet water reaches the contact with the AISI external wall with a time delay of about 1 minute. Therefore, during the first minutes, the heat transfer between the external wall of the CGHE and the ground is not efficient and, as a consequence, the short-circuiting heat transfer between the coaxial tubes plays an important role.

The effects of flow direction and of thermal shortcircuiting are illustrated in Figure 3, where the power exchanged with the ground is plotted versus time, for CGHE 2 in GROUND 2, for both flow configurations, with internal tube in PE-Xa and with an ideal adiabatic internal tube. For the center-in flow configuration, the power is negative for about $90 \mathrm{~s}$. This phenomenon is due to the fact that, while the cold inlet water fills the inner tube, the warm water present in the bulk of the outer tube flows out and heats the cold soil layers which are placed close to the ground surface.

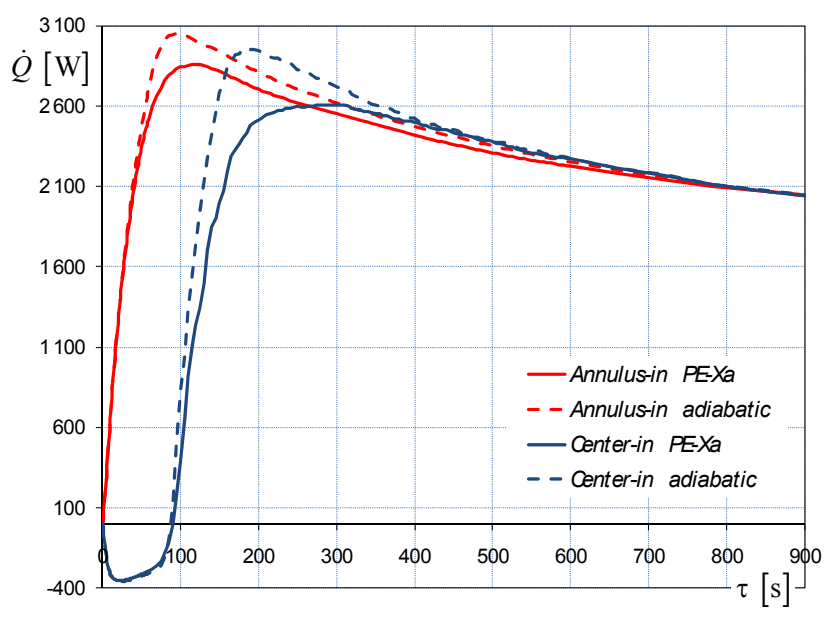

Fig. 3. Power collected by CGHE 2 in GROUND 2, with internal tube in PE-Xa and with adiabatic internal tube.

\section{Increase in thermal performance obtained by CGHE 2}

The basic idea which led us to design CGHE 2 is the following. In CGHE 1, the major part of the distributed pressure drop due to viscous friction occurs in the inner circular tube, where the flow is turbulent with $\mathrm{Re}=6001$. On the contrary, it is better to use the work of the pump to enhance the mean velocity of water in the outer annular passage, where heat transfer with the AISI external wall and thus with the ground occurs. Therefore, the inner tube has been replaced by the next larger one available on the market. In order to keep the total pressure drop nearly unchanged, it has been necessary to replace also the outer AISI tube by the next larger one available on the market. In this way, a $8 \%$ increase of the external area of the CGHE has been produced; a part of the improvement of the thermal performance is due to this increase, which has been necessary to make reference to commercial tubes.

TABLE VI. - Percent energy loss due to thermal shortcircuiting.

\begin{tabular}{|c|c|c|c|c|}
\hline \multicolumn{5}{|c|}{ CGHE 1 - GROUND 1 } \\
\hline & \multicolumn{2}{|c|}{ Annulus-in } & \multicolumn{2}{c|}{ Center-in } \\
\hline Time & $\boldsymbol{P E - X \boldsymbol { a }}$ & $\boldsymbol{P P}-\boldsymbol{R 8 0}$ & $\boldsymbol{P E - X \boldsymbol { a }}$ & $\boldsymbol{P P}-\boldsymbol{R 8 0}$ \\
\hline $300 \mathrm{~s}$ & 2.86 & 1.76 & 11.87 & 9.30 \\
\hline $900 \mathrm{~s}$ & 1.35 & 0.85 & 3.27 & 2.90 \\
\hline $3600 \mathrm{~s}$ & 0.67 & 0.39 & 0.95 & 0.00 \\
\hline $6 \mathrm{~h}$ & 0.57 & 0.46 & 0.41 & 0.06 \\
\hline $24 \mathrm{~h}$ & 0.55 & 0.47 & 0.42 & 0.27 \\
\hline 5 days & 0.35 & 0.28 & 0.76 & 0.68 \\
\hline
\end{tabular}

\begin{tabular}{|c|c|c|c|c|}
\hline \multicolumn{5}{|c|}{ CGHE 1 - GROUND 2 } \\
\hline & \multicolumn{2}{|c|}{ Annulus-in } & \multicolumn{2}{c|}{ Center-in } \\
\hline Time & $\boldsymbol{P E - X \boldsymbol { a }}$ & $\boldsymbol{P P}-\boldsymbol{R} 80$ & $\boldsymbol{P E}-\boldsymbol{X} \boldsymbol{a}$ & $\boldsymbol{P P}-\boldsymbol{R} 80$ \\
\hline $300 \mathrm{~s}$ & 2.88 & 1.86 & 12.06 & 9.52 \\
\hline $900 \mathrm{~s}$ & 1.54 & 1.02 & 3.58 & 3.03 \\
\hline $3600 \mathrm{~s}$ & 0.97 & 0.84 & 1.22 & 0.25 \\
\hline $6 \mathrm{~h}$ & 0.86 & 0.71 & 0.58 & 0.26 \\
\hline $24 \mathrm{~h}$ & 0.87 & 0.64 & 0.50 & 0.46 \\
\hline 5 days & 0.77 & 0.72 & 0.73 & 0.65 \\
\hline
\end{tabular}

\begin{tabular}{|c|c|c|c|c|}
\hline \multicolumn{6}{|c|}{ CGHE 2 - GROUND 1 } \\
\hline & \multicolumn{2}{|c|}{ Annulus-in } & \multicolumn{2}{c|}{ Center-in } \\
\hline Time & $\boldsymbol{P E}-\boldsymbol{X} \boldsymbol{a}$ & $\boldsymbol{P P}-\boldsymbol{R} 80$ & $\boldsymbol{P E}-\boldsymbol{X} \boldsymbol{a}$ & $\boldsymbol{P P}-\boldsymbol{R} 80$ \\
\hline $300 \mathrm{~s}$ & 4.30 & 3.29 & 15.80 & 12.28 \\
\hline $900 \mathrm{~s}$ & 2.63 & 1.92 & 4.38 & 3.42 \\
\hline $3600 \mathrm{~s}$ & 1.12 & 0.26 & 0.94 & 0.19 \\
\hline $6 \mathrm{~h}$ & 0.81 & 0.52 & 0.72 & 0.35 \\
\hline $24 \mathrm{~h}$ & 0.67 & 0.50 & 0.44 & 0.14 \\
\hline 5 days & 0.49 & 0.30 & 0.64 & 0.59 \\
\hline
\end{tabular}

\begin{tabular}{|c|c|c|c|c|}
\hline \multicolumn{6}{|c|}{ CGHE 2 - GROUND 2 } \\
\hline & \multicolumn{2}{|c|}{ Annulus-in } & \multicolumn{2}{c|}{ Center-in } \\
\hline Time & $\boldsymbol{P E}$-Xa & $\boldsymbol{P P - R 8 0}$ & $\boldsymbol{P E}$-Xa & $\boldsymbol{P P - R 8 0}$ \\
\hline $300 \mathrm{~s}$ & 4.47 & 3.53 & 16.60 & 12.78 \\
\hline $900 \mathrm{~s}$ & 2.50 & 2.21 & 4.92 & 3.63 \\
\hline $3600 \mathrm{~s}$ & 0.85 & 1.03 & 1.68 & 1.09 \\
\hline $6 \mathrm{~h}$ & 0.77 & 0.67 & 1.53 & 1.18 \\
\hline $24 \mathrm{~h}$ & 0.68 & 0.54 & 0.97 & 0.64 \\
\hline 5 days & 0.71 & 0.57 & 0.88 & 0.70 \\
\hline
\end{tabular}

The percent difference between the energy collected by CGHE 2 and that collected by CGHE 1 is illustrated in Table VII, with reference to the recommended flow direction, namely the annulus-in configuration.

The results reported in Table VII show that the percent difference between the energy collected by CGHE 2 and that collected by CGHE 1 is significant, especially for short time intervals after the start-up of the CHGE, and is greater for the higher conductivity ground. In GROUND 2 , it is about $20 \%$ for the first 5 minutes, $15-16 \%$ for the first 15 minutes, about $12 \%$ for the first hour and about $6 \%$ for a time interval of 5 days. 
TABLE VII. - Percent difference between the energy collected by CGHE 2 and that collected by CGHE 1, with annulus-in flow direction.

\begin{tabular}{|c|c|c|c|c|}
\hline & \multicolumn{2}{|c|}{ GROUND 1 } & \multicolumn{2}{c|}{ GROUND 2 } \\
\hline Time & PE- $\boldsymbol{X} \boldsymbol{a}$ & PP-R80 & PE-Xa & PP-R80 \\
\hline $300 \mathrm{~s}$ & 19.25 & 19.17 & 20.40 & 20.32 \\
\hline $900 \mathrm{~s}$ & 13.78 & 14.04 & 15.92 & 15.64 \\
\hline $3600 \mathrm{~s}$ & 10.07 & 10.72 & 12.44 & 12.08 \\
\hline $6 \mathrm{~h}$ & 7.18 & 7.37 & 8.83 & 8.77 \\
\hline $24 \mathrm{~h}$ & 5.69 & 5.79 & 7.10 & 7.00 \\
\hline 5 days & 4.50 & 4.62 & 5.80 & 5.89 \\
\hline
\end{tabular}

\section{Conclusions}

The effects of flow direction and of thermal shortcircuiting on the performance of coaxial ground heat exchangers have been studied numerically, by finiteelement simulations performed through the software package COMSOL Multiphysics 3.4. The real 2-D axisymmetric unsteady heat conduction and convection problem has been considered.

Two Coaxial Ground Heat Exchangers (CGHEs) with a length of $20 \mathrm{~m}$ have been examined: the first is a CGHE commonly employed in Northern Italy; the second is an improvement of the first, proposed here. The distribution of the fluid bulk temperature in the inner circular tube has been determined by means of the "weak boundary form" boundary condition available in COMSOL Multiphysics. The laminar convective heat transfer in the outer annular passage has been simulated directly, by assuming a fully developed velocity profile in the whole duct. The computational domain has included the surrounding soil in a radius of $4 \mathrm{~m}$, as well as a $4 \mathrm{~m}$ thick soil layer beneath the CHGE. Two different values of the ground thermal conductivity, as well as two different materials for the inner tube wall have been considered. The results lead to the following conclusions.

The annulus-in flow direction (fluid inlet in the outer annular passage) is more efficient than the center-in flow direction (fluid inlet in the inner circular tube). The effect is important in the first 5 minutes, where it can be higher than $40 \%$, then decreases and becomes lower than $2 \%$ after 6 hours. The effect of short-circuiting is not very important, if the annulus-in flow direction is employed: it has values higher than $4 \%$ only for the more efficient CGHE for a time interval of 5 minutes; then, it decreases rapidly and becomes lower than $1 \%$ for time intervals longer than 1 hour. For the center-in flow direction, the effect of thermal short-circuiting can be very important during the first 5 minutes, where it can exceed $12 \%$.

The enhancement of the thermal performance obtained by means of the new designed CHGE is significant, especially for short time intervals and for high conductivity ground.

\section{References}

[1] 2007 ASHRAE Handbook - HVAC Applications, Ch. 32.

[2] R.L. Ingersoll and A.C. Zobel, Heat conduction with engineering and geological applications, McGraw-Hill, New York (1954).

[3] S.P. Kavanaugh, Simulation and experimental verification of a vertical ground-coupled heat pump system, Ph.D. dissertation, Oklahoma State University, Stillwater, 1985.

[4] S. Gehlin and B. Nordell, "Determining Undistrurbed Ground Temperature for Thermal Response Tests", ASHRAE Transactions, Vol. 109, 151-156 (2003).

[5] P. Roth et al., "First in situ determination of ground and borehole thermal properties in Latin America", Renewable Energy, Vol. 29, pp. 1947-1963 (2004).

[6] S. Signorelli et al., "Numerical evaluation of thermal response tests", Geothermics, Vol. 36, 141-166 (2007).

[7] C. Yavuzturk, J.D. Spitler and S.J. Rees, "A Transient Two-Dimensional Finite Volume Model for the Simulation of Vertical U-tube Ground Heat Exchangers", ASHRAE Transactions, Vol. 105 (2), pp. 465-474 (1999).

[8] W.A. Austin, C. Yavuzturk and J.D. Spitler, "Development of an In-Situ System and Analysis Procedure for Measuring Ground Thermal Properties", ASHRAE Transactions, Vol. 106 (1), pp. 365-379 (2000).

[9] S. Gehlin and G. Hellström, "Comparison of four models for thermal response test evaluation", ASHRAE Transactions, Vol. 109, pp. 131-142 (2003).

[10] H.S. Carlslaw and J.C. Jaeger, Conduction of Heat in Solids, Oxford University Press, Oxford (1959).

[11] H. Zeng, N. Diao and Z. Fang, "Heat transfer analysis of boreholes in vertical ground heat exchangers", Int. J. Heat Mass Transfer, Vol. 46, pp. 4467-4481 (2003).

[12] L. Lamarche and B. Beauchamp, "New solutions for the short-term analysis of geothermal vertical boreholes", Int. J. Heat Mass Transfer, Vol. 50, pp. 1408-1419 (2007).

[13] D. Marcotte and P. Pasquier, "On the estimation of thermal resistance in borehole thermal conductivity test", Renewable Energy, Vol. 33, pp. 2407-2415 (2008).

[14] S. Kakac and Y. Yener, Convective heat transfer, Second Edition, CRC (1995), Section 6-15, pp. 172-179.

[15] S. W. Churchill, "Comprehensive correlating equations for heat, mass and momentum transfer in fully developed flow in smooth tubes", Ind. Eng. Chem. Fundam., Vol. 16, pp. 109-116 (1977).

[16] E. Zanchini, "Mixed convection with variable viscosity in a vertical annulus with uniform wall temperatures", Int. J. Heat Mass Transfer, Vol. 51, pp. 30-40 (2008). 